\title{
BIO-BYWORD
}

\section{HospicNursing of Patients with Advanced Tumor}

\section{Li Jiaxin}

Liaoning Yingkou Hospital of Traditional Chinese Medicine, Yingkou City, Liaoning Province, China

ARTICLE INFO

Article history:

Published online: $30^{\text {th }}$ Sept, 2017

Key words:

Patients with advanced tumor

Hospic nursing

Effect

Corresponding author:

Li Jiaxi,Room 6, Yingkou Hospital of Traditional Chinese Medicine,

No.89, Jianshe Street, Zhanqian District, Yingkou, Liaoning, Email:815160927@qq.com 
Patients with advanced tumor has larger physical and mental pressure, producing negative psychology under the condition of disease, at the same time of suffering pain, patients will bring burdens for the family. In this regard, clinical nursing work should be given comprehensive nursing intervention measures to alleviate the adverse mood of patients, and improve the life quality in patients with advanced tumor. The study will analyze the applying effectiveness of hospic comprehensive nursing intervention measures in patients with advanced tumor.

\section{Data and Method}

\subsection{General data}

Select 108 patients with advanced tumor of the hospital admitted from March 2015 to September, in which there were 64 males and 44 females, aged 58 to 75 years old with the average of $(64.5 \pm 3.5)$ years old. The main tumor types are stomach neoplasm, liver tumor, lung tumor and brain tumor, which severally are 35 cases, 30 cases, 30 cases, and 13 cases. The 108 patients are divided into the control group and the observation group with each 54 cases in each group according to the nursing methods. There is no statistical significance of the difference between the two groups in the baseline data such as age, gender and tumor type $(\mathrm{P}>0.05)$, which can be compared.

\subsection{Method}

\subsubsection{Control group}

Patients take the general nursing measures, for example, trying to meet the needs of patients, to answer questions for patients and their families, or guide medication, etc.

\subsubsection{Observation group}

The patients in the observation group are given hospic comprehensive nursing intervention measure, the specific implementation process: (1) Psychological nursing. Negative emotions such as anxiety, depression are common in patients with advanced tumor, and even the despair performance, such as attachment to life and family. In addition to the economic problems in the treatment, the patients will bear greatly psychological stress. In this regard, nurses need to do a good job of analyzing psychological changes of patients, serving as talk objects of patients to make patients appeal to the inner feelings, which will help patients alleviate the negative psychological. At the same time, encourage relatives and friends often to visit the patients, making them feel the human kindness at the final moment of life ${ }^{[1]}$; (2) life nursing. It mainly means to improve the comfort degree of patients before the death. For this purpose, we can perfect the ward environment, for example, reasonably control the temperature and humidity, keep the light and ventilation, or put flowers, the favorite photos and TV in the ward. At the same time, the nursing staff and family members of patients need to assist patients with good personal hygiene work, often changing the sheets and clothing, and strengthening the nursing of oral care and skin care; (3) pain nursing. Pain symptoms are evident in patients with advanced tumor, usually with increased pain at night, which will affect patients' activities, mood, sleep and many other aspects. In nursing, it can introduce pain transfer measure, such as listening to the radio or playing music, or discussing patients' interest topic to transfer the pain feeling. To the patients with severity degree of pain, adopt step mode of administration according to the doctors' advice, and observe whether the drug produces untoward reactions, etc. ${ }^{22]}$; (4) nutrition nursing. The body function decline is the main feature of patients with advanced tumor. Due to the energy consumption and difficult nutrient absorption, it causes the body nutritional deficiencies. It needs to do the best on the diet guidance in nursing, for example, the food should have high vitamin and high protein and easy to digest, and ensure the fluid balance of patients' body, which will improve the immune function of patients under the nutritional support ${ }^{[3]}$. 


\subsection{Observation indicator}

SAS and SDS are used to evaluate the psychological status of the two groups before and after the nursing. The full score is $80 \times 1.25$, and is divided into three parts: higher than $75,60-75$ and 50-60, corresponding to severe depression, moderate depression and mild depression ${ }^{[4]}$. At the same time, using the quality of life questionnaire-core 30 (QLQ-C30) to compare the life quality status of two groups of patients in the one month nursing ${ }^{[5]}$. The evaluation indexes mainly include physical function, cognitive function, role function, social function and emotional function, and the score of each index is $0-100$. In addition, the self-made questionnaire of hospital are used to survey the satisfaction rate of two groups of patients, including service quality of nursing staff, basic operation and staff attitude, which includes very satisfied and satisfied.

\subsection{Statistical treatment}

Table 1 Comparison of the Improvement Situation of Psychological Status between Two Groups before and after Nursing $\left(\bar{x}_{ \pm \mathrm{s}}\right)$

\begin{tabular}{ccccc}
\hline Group $(\mathrm{n}=54)$ & \multicolumn{2}{c}{ SAS scores (point) } & \multicolumn{2}{c}{ SDS scores (point) } \\
\cline { 2 - 5 } & Before nursing & After nursing & Before nursing & After nursing \\
\hline $\begin{array}{c}\text { Observation } \\
\text { group }\end{array}$ & $63.7 \pm 4.9$ & $40.2 \pm 7.7^{*}$ & $62.7 \pm 7.9$ & $35.8 \pm 6.7^{*}$ \\
$\begin{array}{c}\text { Control group } \\
\text { nyyy }\end{array}$ & $64.6 \pm 4.4$ & $56.7 \pm 5.46$ & $61.8 \pm 7.2$ & $46.1 \pm 8.9$ \\
\hline
\end{tabular}

Note: compared with the control group, ${ }^{*} \mathrm{P}<0.05$.

\subsection{The comparison of the scores of life quality after nursing}

Comparing the scores of life quality of two groups of the observation group is higher than those of the control group, the difference is significant $(\mathrm{P}<0.05)$, which has statistical significance. See Table 2. 
Table 2 The Comparison of the Scores of Life Quality between the Two Group of Patients after Nursing $\left(\bar{x}_{ \pm \mathrm{s}}\right)$

\begin{tabular}{cccccc}
\hline $\begin{array}{c}\text { Group } \\
(\mathrm{n}=54)\end{array}$ & $\begin{array}{c}\text { Physical } \\
\text { function }\end{array}$ & $\begin{array}{c}\text { Cognitive } \\
\text { function }\end{array}$ & Role function & $\begin{array}{c}\text { Social } \\
\text { function }\end{array}$ & $\begin{array}{c}\text { Emotional } \\
\text { function }\end{array}$ \\
\hline $\begin{array}{c}\text { Observation } \\
\text { group }\end{array}$ & $65.2 \pm 2.8^{*}$ & $68.5 \pm 4.5^{*}$ & $67.8 \pm 5.2^{*}$ & $69.7 \pm 4.6^{*}$ & $69.5 \pm 5.5^{*}$ \\
$\begin{array}{c}\text { Control } \\
\text { group }\end{array}$ & $54.6 \pm 3.4$ & $57.6 \pm 3.8$ & $56.5 \pm 4.9$ & $57.9 \pm 3.5$ & $52.8 \pm 4.6$ \\
\hline
\end{tabular}

Notes: compared with the control group, ${ }^{*} \mathrm{P}<0.05$.

\subsection{The comparison of nursing satisfaction rate}

The nursing satisfaction rate of the observation group is $96.30 \%(52 / 54)$, higher than that of the control group
(74.07\% (40/54)), and the difference is significant $(\mathrm{P}<$ 0.05), which is statistically significant. See Table 3.

Table 3 The Comparison of Nursing Satisfaction Rate between Two Groups of Patients [n (\%)]

\begin{tabular}{ccccccc}
\hline $\begin{array}{c}\text { Group } \\
(\mathrm{n}=54)\end{array}$ & $\begin{array}{c}\text { Very } \\
\text { satisfied }\end{array}$ & Satisfied & Normal & Unsatisfied & $\begin{array}{c}\text { Very } \\
\text { unsatisfied }\end{array}$ & $\begin{array}{c}\text { Satisfaction } \\
\text { rate }\end{array}$ \\
\hline $\begin{array}{c}\text { Observatio } \\
\text { n group }\end{array}$ & $38(70.37)$ & 14 & 1 & 1 & 0 & 52 \\
$\begin{array}{c}\text { Control } \\
\text { group }\end{array}$ & $27(50.00)$ & 13 & 8 & 4 & 2 & 40 \\
\hline
\end{tabular}

Notes: compared with the control group, $* \mathrm{P}<0.05$.

\section{Discussion}

\subsection{Physiological responses of patients with advanced tumor}

The adverse emotional problems and life quality problems in patients with advanced tumor are very obvious, and the causes of these problems are mostly attributed to the physiological response of patients. The main responses include: (1) the circulatory system symptoms, such as cold clammy skin, weak pulse, cyanosis of the extremities; (2) the neurological symptoms, such as visual and auditory impairment, consciousness changes, irritability and hyporeflexia, with sleepiness for some patients; (3) the symptoms of respiratory system are mainly characterized by gurgling with sputum and dyspnea, etc. ${ }^{[6]}$; (4) The digestive system symptoms, such as abdominal distension, constipation, vomiting, dehydration, anorexia and other symptoms are obvious. In addition, there are some symptoms in the urinary system and sports system of patients with advanced tumor, for example, the urinary system has uroschesis, incontinentiaurinae and other situations, the sport system has muscular hypotonus and body movement difficulty ${ }^{[7]}$. The symptoms of patients with advanced tumor are the main causes of negative psychological and declining life quality. 


\subsection{Application effect of comprehensive nursing intervention method}

For the problems of low life quality and negative mood of patients with advanced tumor, this study focuses on the patients with the comprehensive nursing intervention method. It can be found that the observation group is superior to the control group in improving the psychological condition and quality of life, and nursing satisfaction rate was higher than the control group, which fully explained the effect obtained under the comprehensive nursing intervention mode is significant. In the actual conduct of nursing work, nursing staff should fully grasp the knowledge of tumor diseases, target to carry out psychological nursing, life nursing, pain nursing and nutrition support, in order to improve the life quality of patients before the death.

In summary, hospic comprehensive nursing intervention applying in patients with advanced tumor can play an important role to improve the life quality and psychological state of patients, and is helpful to improve the patients' satisfaction rate, so it should be applied in nursing practice.

\section{References}

[1] Li Bingjian, Han Lixia, Xu Yuejuan. The Nursing Efficacy of Hospic Care for Patients with Advanced
Tumor [J]. E-Journal of Clinical Medical Literature, 2016, (08): 1475-1476.

[2] Zhuang Yaxian, Min Qifen. Effect of Hospice Care on Life Quality of Patients with Advanced Tumor and Nursing Experience [J] Chinese Journal of Clinical Oncology and Rehabilitation, 2015, (09): 1139-1141.

[3] Zhou Hui, Liu Zengmin. Effect of Hospice Nursing Intervention on Quality of Life of Patients with Advanced Tumor [J]. Chinese and Foreign Medical Research, (2015), (19): 81-83.

[4] $\mathrm{Wu}$ Honghua. The Nursing Efficacy of Hospic Care for Patients with Advanced Tumor [J]. Today Nurse (Middle-monthly), 2015, (02): 65-67.

[[5] Su Lijuan. The Hospic Care Method for Patients with Advanced Tumor [J]. China Practical Medicine, 2014, (30): 223-224.

[6] Su Fang. The Hospic Care of Patients with Advanced Tumor [N]. Journal of Zhejiang Chinese Medicine University, 2013, (06): 821-822.

[7] Li Yunxiang, Zhao ShifengPain Control and Hospice Care in 68 Patients with Advanced Liver Cancer [J]. Chinese Journal of Clinical Oncology and Rehabilitation, 2013, (04): 394-395. 